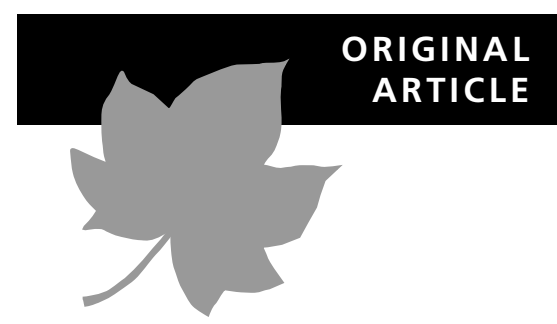

\title{
Nested assemblages of Orthoptera species in the Netherlands: the importance of habitat features and life-history traits
}

\author{
M. A. Schouten ${ }^{1 \star}$, P. A. Verweij ${ }^{2}$, A. Barendregt ${ }^{1}$, R. J. M. Kleukers ${ }^{3}$ and \\ P. C. de Ruiter ${ }^{1}$
}

\begin{abstract}
${ }^{1}$ Department of Environmental Sciences and
${ }^{2}$ Department of Science, Technology and Society, Copernicus Institute for Sustainable Development and Innovation, Utrecht University, PO Box 80115, 3508 TC Utrecht, The Netherlands, ${ }^{3}$ European Invertebrate Survey/EIS Nederland, PO Box 9517, 2300 RA Leiden, The Netherlands
\end{abstract}

\begin{abstract}
Aim Species communities often exhibit nestedness, the species found in speciespoor sites representing subsets of richer ones. In the Netherlands, where intensification of land use has led to severe fragmentation of nature, we examined the degree of nestedness in the distribution of Orthoptera species. An assessment was made of how environmental conditions and species life-history traits are related to this pattern, and how variation in sampling intensity across sites may influence the observed degree of nestedness.
\end{abstract}

Location The analysis includes a total of 178 semi-natural sites in the Pleistocene sand region of the Netherlands.

Methods A matrix recording the presence or absence of all Orthoptera species in each site was compiled using atlas data. Additionally, separate matrices were constructed for the species of suborders Ensifera and Caelifera. The degree of nestedness was measured using the BINMATNEST calculator. BINMATNEST uses an algorithm to sort the matrices to maximal nestedness. We used Spearman's rank correlations to evaluate whether sites were sorted by area, isolation or habitat heterogeneity, and whether species were sorted by their dispersal ability, rate of development or degree of habitat specificity.

Results We found the Orthoptera assemblages to be significantly nested. The rank correlation between site order and sampling intensity was high. The degree of nestedness was lower, but remained significant when under- and oversampled sites were excluded from the analysis. Site order was strongly correlated with both size of sample site and number of habitat types per site. Rank correlations showed that species were probably ordered by variation in habitat specificity, rather than by variation in dispersal capacity or rate of development of the species.

Main conclusions Variation in sampling intensity among sites had a strong impact on the observed degree of nestedness. Nestedness in habitats may underlie the observed nestedness within the Orthoptera assemblages. Habitat heterogeneity is closely related to site area, which suggests that several large sites should be preserved, rather than many small sites. Furthermore, the results corroborate a focus of nature conservation policy on sites where rare species occur, as long as the full spectrum of habitat conditions and underlying ecological processes is secured.

\section{Keywords}

BinMATNest, nature conservation, nestedness, Orthoptera, recording bias, species-area relationship, species occurrence data bases, the Netherlands. 


\section{INTRODUCTION}

It is widely acknowledged that species richness is neither equally nor randomly distributed across the Earth's surface. Since the beginning of the 19th century, scientists have been trying to explain and generalize observed patterns in species richness. One of the general laws in ecology concerns the relationship between species and area. The theory of island biogeography (MacArthur \& Wilson, 1967) attempts to explain the form of the species-area relationship: larger islands will eventually support more species than smaller ones, as the rate of extinction increases with decreasing size. This relationship has been demonstrated for many different taxa and habitat types.

Nested subset theory provides a more comprehensive view on the species-area relationship, incorporating species composition. The nested subset theory refers to the situation where species present at species-poor sites constitute a subset of the species from richer locations (Patterson \& Atmar, 1986). Nested subset structure has been reported for many communities in naturally fragmented landscapes such as islands (Kadmon, 1995; Lomolino, 1996; Yiming et al., 1998) and mountain peaks (Lomolino \& Davis, 1997; Fleishman \& Murphy, 1999; Bruun \& Moen, 2003) as well as anthropogenically fragmented landscapes (Fernández-Juricic, 2002; Fischer \& Lindenmayer, 2005). The literature on nestedness comprises a wide range of taxonomic groups, with an emphasis on birds and mammals. Although several studies incorporate insect data in their analysis, few studies exist where the presence and causes of nestedness within insect assemblages is examined in depth (e.g. Fleishman \& Murphy, 1999; Fleishman et al., 2001, 2002). However, there is a strong need to study insect taxa, as they make up the largest part of known biodiversity, fulfil important ecosystem functions and comprise many endangered species (Ponder \& Lunney, 1999).

Nested subset analyses allow us to study both species richness and species composition at the same time. Therefore nested subset analysis has generated much interest among conservation biologists. Some authors claim that a positive diagnosis on nestedness can, for example, be used as a tool to determine whether it is better to establish a single large reserve or several small ones (Patterson, 1987; Cutler, 1991; Boecklen, 1997). Others find in the observation of nestedness a justification for the use of rare species as indicators for overall species diversity (Fleishman et al., 2002). However, the observation of nested patterns alone does not provide any clues for nature conservation, as long as the mechanisms underlying nestedness are not fully understood (Simberloff \& Martin, 1991). Many studies have tried to elucidate the mechanisms underlying nestedness. The main drivers of nestedness identified so far include selective colonization (Darlington, 1957; Cook \& Quinn, 1995; Kadmon, 1995), selective extinction (Patterson \& Atmar, 1986; Cutler, 1991), nestedness of habitats (Blake, 1991; Cook \& Quinn, 1995; Honnay et al., 1999), interspecific variation in tolerance to environmental conditions (Worthen et al., 1996), and passive sampling
(Andrén, 1994; Cutler, 1994). The latter can cause nestedness as larger areas may contain more species simply by chance, because they constitute larger samples (Connor \& McCoy, 1979; Haila et al., 1993).

In the Netherlands, dense human population and economic growth have altered the natural landscape in fundamental ways, resulting in a reduced overall extent and increased fragmentation of natural areas. We investigated whether the spatial distribution of Orthoptera species in natural areas in the Netherlands is organized in a nested manner, and tried to elucidate the mechanisms that could underlie this type of distribution pattern. Nestedness can be regarded as the result of a species pool being filtered by local environmental conditions, in combination with the ability of the species to cope with these conditions (Wright et al., 1998; Cook et al., 2004). We therefore assessed how nestedness is related to the environmental variables area, spatial heterogeneity and isolation, and to the species life-history traits dispersal ability, rate of development and degree of habitat specificity.

Data on the occurrence of Orthoptera species were derived from a data base of faunistic occurrences in the Netherlands. Although the Netherlands is one of the countries with the most extensive information on biodiversity, unevenness in sampling intensity does pose a problem because data were collected in an ad hoc way. Analogous to passive sampling, variation in sampling intensity among sites may lead to a nested structure in a given data set. At a given sampling intensity, abundant species have a higher probability of being represented in a given biota than rare species (Wright, 1991). With increasing sampling intensity, the chance of encountering rare species increases. Also, vagrant species (one-off occurrences) can cause a major overestimation of, for example, the species richness of a site if sampling effort is excessive (Grinnell, 1922; Williams et al., 2002). Uneven sampling intensity across sites can thus lead to a considerable overestimation of the degree of nestedness. To account for such recording bias, we investigated how differences in sampling intensity across sites influenced the observed nested patterns.

\section{MATERIALS AND METHODS}

\section{Research area}

We selected 178 sites (Fig. 1) on Pleistocene sandy soil with a land cover dominated by semi-natural vegetation types. To this purpose, a grid of $1 \times 1-\mathrm{km}$ squares was superimposed on a detailed digital land-cover map comprising 39 land-cover classes derived from aerial and satellite imagery (Alterra, 2001). We took into account only those grid squares of which $>75 \%$ of the surface was covered by semi-natural vegetation types. Neighbouring grid squares were merged, forming the sampling units of this research.

The sampling sites ranged from 1 to $1081 \mathrm{~km}^{2}$ in size (average $19.75 \mathrm{~km}^{2}$ ). All sites were clearly isolated from each other. The degree of isolation was measured as the distance to 


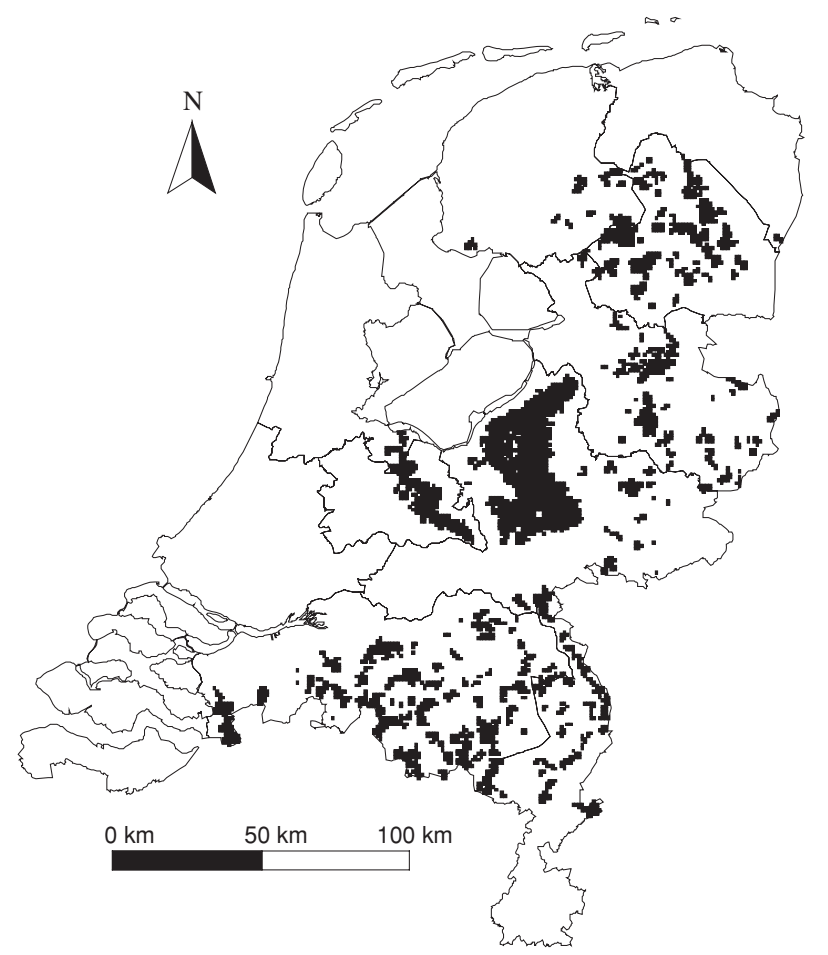

Figure 1 Geographical position of selected sites.

the nearest site. Isolation ranged from 0.1 to $14 \mathrm{~km}$ (average $1.7 \mathrm{~km})$.

From the land-cover map, 13 habitat types (agricultural land, bare soil, coniferous forest, deciduous forest, drift sand, freshwater, heathland, marsh, natural grassland, pasture, peat bog, shrub and urbanized area) were extracted, taking into account Orthoptera requirements. Although somewhat less detailed, this classification largely corresponds to that generally applied for Orthoptera in the Netherlands (Kleukers \& van Nieukerken, 2004). For each site, we counted the number of different habitat types present and calculated Simpson's index of evenness regarding these habitat types:

$$
E_{1 / D}=(1 / D) / S
$$

where $S$ is the number of habitat types in a site, and:

$$
D=\sum\left[n_{i}\left(n_{i}-1\right) / N(N-1)\right]
$$

where $n_{i}=$ the area of the $i$ th habitat type and $N=$ the total area. The measure ranges from 0 to 1 .

\section{Species occurrence data set}

The data on the occurrence of Orthoptera species were derived from the European Invertebrate Survey (EIS Nederland) data base. This data base comprises a diverse assortment of museum records, data from monitoring schemes, species lists of inventory trips, and incidental occurrence records collected over more than a century by many volunteers. These data were usually collected in a rather ad hoc fashion, resulting in taxonomically, geographically and temporally biased records (Rich, 1998; Dennis et al., 1999). Therefore the data quality varies, and the available records of species occurrences may not adequately reflect species composition of a given location. Nevertheless, this is the only type of nationwide data available.

The Orthoptera species occurrence data set contains about 85,500 records on the distribution of 45 species, collected between 1900 and 2002. For this study we used only the post1965 data, as the older data are probably no longer representative because of the major land-use changes of the 1960s: environmental conditions in the Netherlands have gradually changed since then. However, there is always a trade-off between data quantity and accuracy with the kind of data used in this study. Species-occurrence data are available at a resolution of $1 \times 1 \mathrm{~km}^{2}$ and are tabulated in a presenceabsence matrix. For species names and the division into suborders, we followed the taxonomy of Rentz (1991). The degree of habitat specificity (Table 1) was derived from the distribution atlas (Kleukers \& van Nieukerken, 2004). For all other data on the life-history traits of the individual species, we relied on the expert knowledge provided by EIS Nederland.

\section{Analytical methods}

\section{Quantification of nestedness}

To quantify the level of nestedness, a large number of metrics have been proposed (e.g. Wright et al., 1998; RodríguezGironés \& Santamaría, 2006). In this study we used the binary matrix nestedness temperature calculator (BINMATNEST; Rodríguez-Gironés \& Santamaría, 2006). BINMATNEST is a recent improvement of the nested-temperature method of Atmar \& Patterson (1993), using a more robust algorithm for matrix packing. In BINMATNEST, rows and columns are permuted in such a way that matrix nestedness is maximized: ordering is not done according to species richness or site area. BINMATNEST calculates a temperature (ranging from 0 to $100^{\circ} \mathrm{C}$ ) of the deviation of a particular data set from the ideal nested structure. Deviation from perfect nestedness is assessed by comparing the observed species occurrence matrix, rearranged to gain maximum order, with a perfectly nested matrix with the same rank and fill. Highly nested assemblages, exhibiting fewer deviations from perfect nestedness, therefore score a lower temperature than less nested assemblages with many deviations. To determine the statistical significance of the observed matrix temperature, it is compared with the distribution of simulated temperatures produced by randomization (100 iterations) of the matrix. In the null model applied, the probability of each cell being occupied is the average of the probabilities of occupancy of its row and column.

\section{Determinants of nestedness}

The order in which sites and species are sorted by the BINMATNEST algorithm can be compared with numerous 


\begin{tabular}{|c|c|c|c|c|}
\hline Species & $\begin{array}{l}\text { Rate of } \\
\text { development }\end{array}$ & $\begin{array}{l}\text { Habitat } \\
\text { specificity }\end{array}$ & $\begin{array}{l}\text { Dispersal } \\
\text { capacity }\end{array}$ & $\begin{array}{l}\text { Passive } \\
\text { dispersal }\end{array}$ \\
\hline \multicolumn{5}{|l|}{ Ensifera } \\
\hline Acheta domesticus & 6 & 1 & 1 & $\mathrm{Y}$ \\
\hline Conocephalus discolor & 12 & 3 & 3 & \\
\hline Conocephalus dorsalis & 12 & 4 & 3 & \\
\hline Decticus verrucivorus & 24 & 3 & 2 & \\
\hline Ephippiger ephippiger & 24 & 1 & 1 & \\
\hline Gampsocleis glabra & 24 & 1 & 2 & \\
\hline Gryllotalpa gryllotalpa & 24 & 1 & 2 & $\mathrm{Y}$ \\
\hline Gryllus campestris & 12 & 2 & 3 & \\
\hline Leptophyes punctatissima & 12 & 4 & 1 & $\mathrm{Y}$ \\
\hline Meconema thalassinum & 12 & 4 & 3 & \\
\hline Metrioptera brachyptera & 24 & 1 & 2 & \\
\hline Metrioptera roeselii & 12 & 2 & 3 & \\
\hline Nemobius sylvestris & 24 & 2 & 1 & \\
\hline Phaneroptera falcata & 12 & 2 & 3 & \\
\hline Pholidoptera griseoaptera & 24 & 3 & 1 & $\mathrm{Y}$ \\
\hline Tettigonia cantans & 24 & 1 & 1 & \\
\hline Tettigonia viridissima & 24 & 6 & 3 & \\
\hline \multicolumn{5}{|l|}{ Caelifera } \\
\hline Chorthippus albomarginatus & 12 & 2 & 2 & \\
\hline Chorthippus biguttulus & 12 & 5 & 3 & \\
\hline Chorthippus brunneus & 12 & 5 & 3 & \\
\hline Chorthippus mollis & 12 & 3 & 2 & \\
\hline Chorthippus montanus & 12 & 2.5 & 2 & \\
\hline Chorthippus parallelus & 12 & 2 & 3 & \\
\hline Chorthippus vagans & 12 & 3 & 2 & \\
\hline Chrysochraon dispar & 12 & 2 & 2 & \\
\hline Myrmeleotettix maculatus & 12 & 2 & 1 & \\
\hline Oedipoda caerulescens & 12 & 2 & 2 & \\
\hline Omocestus rufipes & 12 & 2 & 2 & \\
\hline Omocestus viridulus & 12 & 2 & 2 & \\
\hline Stenobothrus lineatus & 12 & 1.5 & 2 & \\
\hline Stenobothrus stigmaticus & 12 & 1.5 & 1 & \\
\hline Stethophyma grossum & 12 & 3 & 2 & \\
\hline Tetrix bipunctata & 12 & 1 & 2 & \\
\hline Tetrix ceperoi & 12 & 2 & 3 & \\
\hline Tetrix subulata & 12 & 3 & 3 & \\
\hline Tetrix tenuicornis & 12 & 3 & 2 & \\
\hline Tetrix undulata & 12 & 3 & 2 & \\
\hline
\end{tabular}

Table 1 Life-history traits of Orthoptera species.

Rate of development in months, habitat specificity ranked 1 (highly specific) to 6 (generalists). Dispersal capacity: 1 = without wings, not very mobile; 2 = sometimes with functional wings, not found outside the mating biotope; 3 = (sometimes) with functional wings, regularly found outside the mating biotope. Passive dispersal by humans, animals, floating, etc: $\mathrm{Y}=$ yes.

possible independent correlates. Spearman's rank correlation was used to evaluate the influence of site area, habitat heterogeneity and isolation, and of species dispersal ability, rate of development and habitat specificity on the degree of nestedness of the assemblages. From the presence-absence matrix packed to maximal nestedness by BINMATNEST, we took the resulting site order and successively compared it with the area, degree of isolation and heterogeneity of the sites. The same procedure was followed for species order according to BINMATNEST, and species dispersal ability, rate of development and habitat specificity. A significant correlation between the species and site order according to BINMATNEST, and their order in accordance with a given factor, indicates a possible influence of that factor on the formation of the nested structure (Patterson \& Atmar, 2000).

\section{Coping with differences in sampling intensity}

Uneven distribution of recording data is a well known problem with the kind of species-occurrence data bases used in this study (Rich, 1998; Dennis et al., 1999). To identify the effect of differences in sampling intensity among sites on the observed 
patterns, we calculated the sampling intensity (number of records per $\mathrm{km}^{2}$ ) for each site. In three steps, we then removed the 5th, 10th and 25th upper and lower percentiles of the sites ranked according to their sampling intensity, thus filtering out both undersampled and oversampled sites.

\section{RESULTS}

The Orthoptera assemblages were significantly nested $(T=7.90$; Table 2$)$. The pattern was even more strongly expressed when only the species belonging to suborder Ensifera were taken into account $(T=3.31)$. The degree of nestedness of species assemblages of the suborder Caelifera did not differ much from that of the Orthoptera taxon as a whole $(T=8.12)$. It should be noted, however, that a straightforward comparison of nestedness temperatures is difficult because of minor differences in matrix size and fill (Greve \& Chown, 2006; Rodríguez-Gironés \& Santamaría, 2006). When sites with extreme sampling intensities were excluded from the analysis, the degree of nestedness decreased. Temperature rose to $13.34^{\circ} \mathrm{C}$ for the entire Orthoptera matrix (Table 2; Appendix S1 in Supplementary Material) when filtering out under- and oversampled sites. This suggests that differences in sampling intensity can result in a considerable overestimation of the degree of nestedness. However, the degree of nestedness within the more evenly sampled sites remained significant $(P<0.001)$.

Spearman's rank correlation indicated that the site order, as determined by BINMATNEST, was very similar to the order obtained when ordering the sites in accordance with their area, sampling intensity, or number of different habitat types present (Table 3). The correlations between site order and degree of isolation, and between site order and Simpson's index of habitat heterogeneity, are less strong. When stepwise omitting sites with low (5th, 10th, 25th percentiles) and high (95th, 90th, 75th percentiles) sampling intensity from the analysis, the influence of sampling intensity declined until it became non-significant. Site order then correlated most strongly with area $(0.810, P<0.01$, Spearman's correlation) and the number of different habitat types $(0.594, P<0.01$, Spearman's correlation). However, it should be noted that area and the number of habitat types present in that site are themselves correlated $(0.671, P<0.01$, Spearman's correlation). Heterogeneity of habitat types $(E)$ was negatively
Table 2 Summary of results obtained from calculation of nestedness temperature $T\left({ }^{\circ} \mathrm{C}\right)$ of Orthoptera matrices.

\begin{tabular}{llllr}
\hline & $\begin{array}{l}\text { Number of } \\
\text { species }\end{array}$ & $\begin{array}{l}\text { Number of } \\
\text { areas }\end{array}$ & $\begin{array}{l}\text { Fill } \\
(\%)\end{array}$ & $T\left({ }^{\circ} \mathrm{C}\right)$ \\
\hline All species & & & & \\
$\quad$ All areas & 37 & 178 & 24.4 & $7.90^{* *}$ \\
$\quad$ Upper and lower 5th percentile excluded & 37 & 160 & 24.9 & $8.67^{* *}$ \\
$\quad$ Upper and lower 10th percentile excluded & 36 & 144 & 25.3 & $10.34^{* *}$ \\
$\quad$ Upper and lower 25th percentile excluded & 32 & 84 & 28.3 & $13.34^{* *}$ \\
Caelifera & & & & \\
$\quad$ All areas & 20 & 175 & 30.5 & $8.12^{* *}$ \\
$\quad$ Upper and lower 25th percentile excluded & 18 & 84 & 34.3 & $11.89^{* *}$ \\
Ensifera & 17 & 164 & 19.4 & $3.31^{* *}$ \\
$\quad$ All areas & & 81 & 21.3 & $4.56^{* *}$ \\
$\quad$ Upper and lower 25th percentile excluded & 14 & & &
\end{tabular}

Different sets of areas are analysed according to sampling intensity. All results presented here correspond to PopSize $=35$, TourSize $=7$ and nbGen $=5000 .{ }^{* *} P<0.001$.

\begin{tabular}{|c|c|c|c|c|c|}
\hline & $\begin{array}{l}\text { Area } \\
\text { size } \\
\left(\mathrm{km}^{2}\right)\end{array}$ & $\begin{array}{l}\text { Isolation } \\
(\mathrm{km})\end{array}$ & $\begin{array}{l}\text { Number } \\
\text { of habitat } \\
\text { types }\end{array}$ & $\begin{array}{l}\text { Simpson's index } \\
\text { of evenness in } \\
\text { habitat }\end{array}$ & $\begin{array}{l}\text { Sampling } \\
\text { intensity }\end{array}$ \\
\hline \multicolumn{6}{|l|}{ All species } \\
\hline All areas & $0.642^{* *}$ & $-0.194^{\star *}$ & $0.406^{* *}$ & $-0.202^{\star *}$ & $0.503^{* *}$ \\
\hline Equally sampled areas & $0.810^{* *}$ & $-0.347^{\star *}$ & $0.594^{* *}$ & $-0.431^{\star *}$ & 0.07 \\
\hline \multicolumn{6}{|l|}{ Caelifera } \\
\hline All areas & $0.637^{\star *}$ & $-0.249^{\star *}$ & $0.515^{* *}$ & $-0.193^{\star *}$ & $0.578^{\star *}$ \\
\hline Equally sampled areas & $0.695^{\star *}$ & $-0.410^{\star *}$ & $0.608^{* *}$ & $-0.438^{\star *}$ & 0.115 \\
\hline \multicolumn{6}{|l|}{ Ensifera } \\
\hline All areas & $0.495^{\star *}$ & -0.119 & $0.225^{\star *}$ & $-0.173^{\star *}$ & $0.401^{\star \star}$ \\
\hline Equally sampled areas & $0.559^{* *}$ & -0.174 & $0.240^{\star}$ & $-0.254^{\star}$ & 0.106 \\
\hline
\end{tabular}

Correlation significant at ${ }^{\star} 0.05$ level; ${ }^{\star *} 0.01$ level.
Table 3 Relationships (Spearman's $R$ rank correlations) between ranking order of areas after packing to maximal nestedness using BINMATNEST and order of areas after rearranging the matrix regarding the explanatory variables. 
Table 4 Relationships (Spearman's $R$ rank correlations) between ranking order of species after packing to maximal nestedness using BINMATNEST and order of species after rearranging the matrix according to life-history traits (Table 1).

\begin{tabular}{llll}
\hline & $\begin{array}{l}\text { Rate of } \\
\text { development }\end{array}$ & $\begin{array}{l}\text { Dispersal } \\
\text { capacity }\end{array}$ & $\begin{array}{l}\text { Habitat } \\
\text { specificity }\end{array}$ \\
\hline All species & & & \\
$\quad$ All areas & -0.210 & $0.290^{* *}$ & $0.486^{* *}$ \\
$\quad$ Equally sampled areas & -0.07 & 0.167 & $0.415^{* *}$ \\
Caelifera & - & 0.233 & 0.349 \\
$\quad$ All areas & - & 0.180 & 0.361 \\
$\quad$ Equally sampled areas & -0.224 & 0.364 & $0.619^{* *}$ \\
Ensifera & All areas & 0.207 & $0.495^{*}$ \\
$\quad$ Equally sampled areas & 0.040 & & \\
\hline
\end{tabular}

Correlation significant at ${ }^{\star} 0.05$ level; ${ }^{* *} 0.01$ level.

correlated with site order, and this correlation was weaker than between site order and the number of habitat types present in a site. Dividing the Orthoptera into the suborders Caelifera and Ensifera produced similar results, with the difference that site order for the Caelifera was more strongly associated to the number of habitat types per site than for the Ensifera assemblages.

Table 4 shows how species order according to life-history traits correlates with the observed rank order produced by BINMATNEST. The correlation between species order and lifehistory traits is weaker than the correlation between site order and environmental factors. Nevertheless, we found a significant correlation of species order and habitat specificity, and of species order and dispersal capacity. However, dispersal capacity was no longer significantly correlated with species order when under- and oversampled sites were excluded from the analysis. Habitat specificity of the individual species is the factor most probably promoting nestedness within the Orthoptera assemblages. When all species are taken into account, we found a correlation of $0.415(P<0.01)$ between species order and habitat specificity. For the Ensifera, this correlation appeared to be somewhat higher, but of less strong significance $(0.495, P<0.05)$.

\section{DISCUSSION}

We found a high degree of nestedness within the Orthoptera assemblages. This pattern was expressed most strongly when only the species belonging to the suborder Ensifera were taken into account. The difference between the Caelifera and Ensifera assemblages can be explained from life-history traits of the species. The Ensifera species are highly diverse, varying in body size and having a broad range of diet preferences. The eggs of some Ensifera species can be dispersed passively over large distances (Table 1). The Caelifera also show a large variety in body size, but feed only on plant material and overall have a lower dispersal capacity (Table 1). Thus the Ensifera assemblages depend on a broader range of resources and have a wider dispersal range, and would be expected to show a more nested pattern than the Caelifera assemblages.

From an environmental perspective, three factors may explain the nestedness of the Orthoptera species assemblages: area, habitat heterogeneity and isolation. All three factors showed a significant correlation with site order. Variation in the number of different habitat types in a site proved to be more important for the occurrence of nested patterns than the spatial arrangement of these habitat types in terms of heterogeneity. The heterogeneity index scored lower and, moreover, was negatively correlated with site order. This suggests that species richness would be higher in sites of a given cover type, rather than a large diversity of small fragments. Area was found to be the most important factor that could have caused the nested pattern. From a species perspective, however, the number of different habitat types appears to be more important because the relation of species order with habitat specificity is very strong. Also, it is unlikely that insects such as Orthoptera, with a relatively small range size, would need large sites $\left(>1 \mathrm{~km}^{2}\right)$ to sustain healthy populations. Köhler (1996), for example, assessed the population vulnerability of Orthoptera in highly fragmented Central European landscapes and found that some small populations (50-200 specimens) can persist for a long time in very small habitats $\left(100-600 \mathrm{~m}^{2}\right)$. However, hardly any research has been done on the relationship between the size of a given site and the survival chances of Orthoptera populations, therefore generalizations cannot be made. There is a strong correlation between area and number of habitat types: as the area increases, more habitat types occur. Also, the number of species-occurrence records is correlated with the size of nature areas. Therefore it is difficult to distinguish which part of variation in species diversity is explained by factors correlated with size, and which part is a true effect of area. The exact role played by area in the formation of nested patterns remains unclear, as we were unable to identify life-history traits correlated with area. However, there are strong indications that the effect of area is merely caused by the increasing number of habitat types.

Fleishman and co-workers (Fleishman et al., 2001, 2002; Fleishman \& Murphy, 1999) studied in detail the presence and causes of nestedness within insect assemblages. In their study on the butterflies of the mountain ranges in the Great Basin of western North America, these authors found a high degree of nestedness. Selective dispersal seemed to play a minor role; several environmental variables had an effect on the occurrence of nested pattern formation, although their importance varied. Also in their study, area had an effect on nestedness but its influence varied among mountain ranges. Studies on the nestedness of non-insect taxa in fragmented landscapes (Herkert, 1994; Lomolino \& Davis, 1997; Mac Nally et al., 2002; Fernández-Juricic, 2004) included a broad spectrum of factors (e.g. heterogeneity, disturbance, isolation), but predominantly pointed towards area as the important factor inducing nested patterns. However, several 
authors (e.g. Berglund \& Jonsson, 2003; Hylander et al., 2005) found that nestedness also occurs within sites of uniform size. The latter confirms our presumption that the number of different habitat types present plays a more important role than area as such.

Rank correlations showed a close relationship between the ordering of sites and the amount of sampling effort put into those sites, a phenomenon also observed by Cook et al. (2004). Broad-scale data bases of collecting events, as used in this study, are inaccurate because of bias in sampling effort. Such data bases often do not contain information about real absences of species (Rich, 1998); moreover, sampling intensity is usually biased towards the richest sites (Dennis \& Thomas, 2000). This makes it difficult, if not impossible, to estimate true sampling intensity or to distinguish the undersampled sites from well sampled or even oversampled ones. Sampling effort may have a considerable impact on the resulting record of species richness and composition of a given site (Dennis et al., 1999). To evaluate the effects of differences in sampling intensity, we investigated how nested temperatures reacted after removing from the analysis sites with both low and high sampling intensity. This revealed that differences in sampling intensity can lead to an overestimation of the degree of nestedness.

The high degree of nestedness within the Orthoptera assemblages, and the strong influence of area and habitat heterogeneity on the formation of this pattern, may have implications for nature conservation in the Netherlands. Area and, accordingly, diversity of habitats, appeared to be more important for the occurrence of nested patterns than the degree of isolation of sites. This suggests that large, diverse nature areas are expected to be effective in preserving entire assemblages of Orthoptera. However, as we do not have information on population viability or corridor effects, it is not clear whether it is more effective to enlarge or to interconnect small conservation areas. Moreover, nestedness analysis is probably not the most suitable tool for effective reserve design (Simberloff \& Martin, 1991; Whittaker, 1998). Nestedness analysis certainly is an important compositional descriptor, and can give clues for nature conservation, but complementarity algorithms, for example (Williams et al., 2005) provide a better tool to optimize conservation efforts.

Nestedness analyses apply to relatively homogeneous ecological regions. Therefore the outcomes of this study relate only to a specific part of the Netherlands. Our results provide support for the current nature conservation policy of the Netherlands, which is focused on the conservation of the so-called ITZ species: species for which the Netherlands carries an international responsibility (I); species with a strong decline due to habitat loss $(\mathrm{T})$; and rare species $(\mathrm{Z})$. This study shows that, by protecting sites where rare species with narrow habitat requirements occur, a broad array of less selective species are expected to be protected as long as the full spectrum of habitat conditions and ecological processes is secured.

\section{ACKNOWLEDGEMENTS}

We are grateful to Miguel Rodriguez-Gironés and an anonymous referee for their valuable comments. Arnold de Boer and Robert Brinkman are thanked for critically reading the manuscript.

\section{REFERENCES}

Alterra (2001) Het Landelijk grondgebruiksbestand Versie 4 (LGN4). Centrum voor Geo-informatic, Wageningen, The Netherlands.

Andrén, H. (1994) Can one use nested subset pattern to reject the random sample hypothesis? Examples from boreal bird communities. Oikos, 70, 489-491.

Atmar, W. \& Patterson, B.D. (1993) The measure of order and disorder in the distribution of species in fragmented habitat. Oecologia, 96, 373-382.

Berglund, H. \& Jonsson, B.G. (2003) Nested plant and fungal communities; the importance of area and habitat quality in maximizing species capture in boreal old-growth forests. Biological Conservation, 112, 319-328.

Blake, J.G. (1991) Nested subsets and the distribution of birds on isolated woodlots. Oecologia, 5, 58-66.

Boecklen, W.J. (1997) Nestedness, biogeographic theory, and the design of nature reserves. Oecologia, 112, 123-142.

Bruun, H.H. \& Moen, J. (2003) Nested communities of alpine plants on isolated mountains: relative importance of colonization and extinction. Journal of Biogeography, 30, 297-303.

Connor, E.F. \& McCoy, E.D. (1979) The statistics and biology of the species-area relationship. The American Naturalist, 113, 791-833.

Cook, R.R. \& Quinn, J.F. (1995) The influence of colonization in nested species subsets. Oecologia, 102, 413-424.

Cook, R.R., Angermeier, P. L., Finn, D.S., Poff, N.L. \& Krueger, K.L. (2004) Geographic variation in patterns of nestedness among local stream fish assemblages in Virginia. Oecologia, 140, 639-649.

Cutler, A. (1991) Nested faunas and extinction in fragmented habitats. Conservation Biology, 5, 496-505.

Cutler, A.H. (1994) Nested biotas and biological conservation: metrics, mechanisms, and meaning of nestedness. Landscape and Urban Planning, 28, 73-82.

Darlington, P.J., Jr (1957) Zoography: the geographical distribution of animals. John Wiley, New York.

Dennis, R.L.H. \& Thomas, C.D. (2000) Bias in butterfly distribution maps: the influence of hot spots and recorder's home range. Journal of Insect Conservation, 4, 73-77.

Dennis, R.L.H., Sparks, T.H. \& Harvey, P.B. (1999) Bias in butterfly distribution maps: the effects of sampling effort. Journal of Insect Conservation, 3, 33-42.

Fernández-Juricic, E. (2002) Can human disturbance promote nestedness? A case study with breeding birds in urban habitat fragments. Oecologia, 131, 269-278.

Fernández-Juricic, E. (2004) Spatial and temporal analysis of the distribution of forest specialists in an urban-fragmented 
landscape (Madrid, Spain). Implications for local and regional bird conservation. Landscape and Urban Planning, 69, 17-32.

Fischer, J. \& Lindenmayer, D.B. (2005) Nestedness in fragmented landscapes: a case study on birds, arboreal marsupials and lizards. Journal of Biogeography, 32, 1737-1750.

Fleishman, E. \& Murphy, D.D. (1999) Patterns and processes of nestedness in a Great Basin butterfly community. Oecologia, 119, 133-139.

Fleishman, E., Austin, G.T. \& Murphy, D.D. (2001) Biogeography of Great Basin butterflies: revisiting patterns, paradigms, and climate change scenarios. Biological Journal of the Linnean Society, 74, 501-515.

Fleishman, E., Betrus, C.J., Blair, R.B., Mac Nally, R. \& Murphy, D.D. (2002) Nestedness analysis and conservation planning: the importance of place, environment, and life history across taxonomic groups. Oecologia, 133, 78-89.

Greve, M. \& Chown, S.L. (2006) Endemicity biases nestedness metrics: a demonstration, explanation and solution. Ecography, 29, 347-356.

Grinnell, J. (1922) The role of the 'accidental'. The Auk, 49, 373-380.

Haila, Y., Hanski, I.K. \& Raivo, S. (1993) Turnover of breeding birds in small forest fragments: the sampling colonization hypothesis corroborated. Ecology, 74, 714-725.

Herkert, J.R. (1994) The effects of habitat fragmentation on midwestern grassland bird communities. Ecological Applications, 4, 461-471.

Honnay, O., Hermy, M. \& Choppin, P. (1999) Nested plant communities in deciduous forest fragments: species relaxation or nested habitats? Oikos, 84, 119-129.

Hylander, K., Nilsson, C., Jonsson, B.G. \& Göthner, T. (2005) Differences in habitat quality explain nestedness in a land snail meta-community. Oikos, 108, 351-361.

Kadmon, R. (1995) Nested species subsets and geographic isolation: a case study. Ecology, 76, 458-465.

Kleukers, R.M.J.C. \& van Nieukerken, E.J. (2004) De sprinkhanen en krekels van Nederland: (Orthoptera), 2nd edn. Nationaal Natuurhistorisch Museum Naturalis, KNNV Uitgeverij \& European Invertebrate Survey-Nederland, Leiden.

Köhler, G. (1996) The ecological background of population vulnerability in Central European grasshoppers and bushcrickets: a brief review. Species survival in fragmented landscapes (ed. by J. Settle, C. Margules, P. Poschold and K. Henle), pp. 290-298. Kluwer Academic, Dordrecht.

Lomolino, M.V. (1996) Investigating causality of nestedness of insular communities: selective immigrations or extinctions? Journal of Biogeography, 23, 699-703.

Lomolino, M.V. \& Davis, R. (1997) Biogeographic scale and biodiversity of mountain forest mammals of western North America. Global Ecology and Biogeography Letters, 6, 57-76.

Mac Nally, R., Horrocks, G. \& Bennett, A.F. (2002) Nestedness in fragmented landscapes: birds of the box-ironbark forests of south-eastern Australia. Ecography, 25, 651-660.
MacArthur, R.H. \& Wilson, E.O. (1967) The theory of island biogeography. Princeton University Press, Princeton.

Patterson, B.D. (1987) The principle of nested subsets and its implications for biological conservation. Conservation Biology, 1, 323-334.

Patterson, B.D. \& Atmar, W. (1986) Nested subsets and the structure of insular mammalian faunas and archipelagos. Biological Journal of the Linnean Society, 28, 65-82.

Patterson, B.D. \& Atmar, W. (2000) Analyzing species composition in fragments. Isolated vertebrate communities in the tropics (ed. by G. Rheinwald), pp. 9-24. Bonn Zoological Monographs 46. Alexander Koening Zoological Research Institute and Zoological Museum, Bonn.

Ponder, W. \& Lunney, D. (1999) The other 99\% - the conservation and biodiversity of invertebrates. Mosman, Australia.

Rentz, D.C.F. (1991) Orthoptera (grasshoppers, locusts, katydids and crickets). The insects of Australia (ed. by I. D. Naumann), pp. 369-393. CSIRO/Melbourne University Press, Melbourne.

Rich, T.C.G. (1998) Squaring the circles - bias in distribution maps. British Wildlife, 9, 213-219.

Rodríguez-Gironés, M.A. \& Santamaría, L. (2006) A new algorithm to calculate the nestedness temperature of presence-absence matrices. Journal of Biogeography, 33, 924-935.

Simberloff, D. \& Martin, J-L. (1991) Nestedness of insular avifaunas: simple summary statistics masking complex species patterns. Ornis Fennica, 68, 178-192.

Whittaker, R.J. (1998) Island biogeography: ecology, evolution, and conservation. Oxford University Press, Oxford.

Williams, P.H., Margules, C.R. \& Hilbert, D.W. (2002) Data requirements and data sources for biodiversity priority area selection. Journal of Biosciences, 27, 327-338.

Williams, P.H., Faith, D., Manne, L., Sechrest, W. \& Preston, C. (2005) Complementarity analysis: mapping the performance of surrogates for biodiversity. Biological Conservation, 128, 253-246.

Worthen, W.B., Carswell, M.L. \& Kelly, K.A (1996) Nested subset structure of larval mycophagous fly assemblages: nestedness in a non-island system. Oecologia, 107, 257-264.

Wright, D.H. (1991) Correlations between incidence and abundance are expected by chance. Journal of Biogeography, 18, 463-466.

Wright, D.H., Patterson, B.D., Mikkelson, G.M., Cutler, A. \& Atmar, W. (1998) A comparative analysis of nested subset patterns of species composition. Oecologia, 113, $1-20$.

Yiming, L., Niemelä, J. \& Dianmo, L. (1998) Nested distribution of amphibians in the Zhoushan archipelago, China: can selective extinction cause nested subsets of species? Oecologia, 113, 557-564.

\section{SUPPLEMENTARY MATERIAL}

The following supplementary material is available for this article online: 
Appendix S1 Species-occurrence matrix.

This material is available as part of the online article from: http://www.blackwell-synergy.com/doi/abs/10.1111/j.1365-2699. 2007.01742.x
Please note: Blackwell Publishing are not responsible for the content or functionality of any supplementary materials supplied by the authors. Any queries (other than missing material) should be directed to the corresponding author for the article.

\section{BIOSKETCHES}

Marieke A. Schouten is a PhD researcher at Utrecht University, working on spatial patterns of species richness in the Netherlands. She is interested in biodiversity information management and the effects of natural and human-driven environmental changes on species diversity.

Pita A. Verweij is a landscape ecologist at the Copernicus Institute of Utrecht University. She is interested in spatial modelling of biodiversity patterns, land-use impacts on ecosystems, and nature conservation policy.

Aat Barendregt is an ecologist working as senior lecturer in Environmental Sciences. His research interests concentrate on interdisciplinary studies in wetlands, nature conservation problems and entomology.

Editor: Melodie McGeoch 